\title{
2214 車載用フライホイールのエネルギ貯蔵特性とジャイロによる横転防止システム に関する研究
}

Study on characteristics of flywheel energy storage system for vehicles and on rollover prevention

$$
\begin{gathered}
\text { フェロー 須田義大（東大） } \\
\text { 正 王 文軍（東大） 安藤孝幸（東大） 小谷 学（東大） }
\end{gathered}
$$

Yoshihiro SUDA, Center for Collaborative Research, University of Tokyo, 4-6-1 Komaba, Meguro-ku, Tokyo

Takayuki ANDO, Graduate School, University of Tokyo

Manabu KOTANI, Graduate School, University of Tokyo

Wang Wenjun, Graduate School, University of Tokyo

Kimihiko NAKANO, Institute of Industrial Science, University of Tokyo

\begin{abstract}
This paper proposes a new method to control of heavy vehicles for prevent of turn over using gyroscopic moment. In the proposed method the gyroscopic moment is assumed to be generated by the flywheel, which could be applied to vehicles as energy storage device. The simple two degrees of freedom analytical model was derived to examine theoretically and the parameters of flywheel system are referred to the real system which was introduced in our Chiba Experiment Station. Vehicle dynamics model is modeled by multibody dynamics software "SIMPACK" and the control performance was examined. Finally, the compatibility between gyro actuator and flywheel system for energy stores of braking of the vehicle is evaluated by numerical simulation under the assumption of actual operation mode. It was found that the proposed control system is effective for prevention of roll turn over and energy storage system.
\end{abstract}

Key words: Roll Over prevention, Heavy Vehicle, Gyro, Flywheel, Energy Storage, CFRP

\section{1. 緒言}

近年，車両のピークエネルギ平準化や制動時のエネルギ回 生を行い，エネルギの有効活用を図ることを目的としたハイ ブリッドシステムの研究開発が国内外で行われている. 八イ ブリッドシステムにおけるエネルギ貯蔵装置として，一般的 にはバッテリが検討されているが, 寿命やエネルギ密度など の観点から, 力学的エネルギとして貯蔵するフライホイール の優位性も指摘されている(1). 従来, エネルギ貯蔵用フライ ホイールは車両の運動に対し，ジャイロ効果による影響を及 ぼさないようにダブルジンバル支持により車載されてきた.

一方，回転体としての性質を活用すれば車両の運動を積極的 に制御できると考えられる. れまでに, 受動形式のジャイロ 制振機構として, 船舶の減摇装置や索道器の減摇, および鉄 道車両の蛇行動の抑制, また, 能動形式のジャイロ制振機構 として, 宇宙構造物の姿勢制御などの研究が行われた ${ }^{(2)(3)(4)(5) . ~}$

筆者らは、フライホイール式エネルギ眝蔵装置をジャイロ 機能を用いて車両の制御に適用することを提案し、鉄道車両 の車体傾斜制御一の適用や，大型貨物車両や連結車の転倒防 止制御一の応用を検討してきた ${ }^{(6)(7)(8)}$ 。本研究では、大型車の 横転防止への有効性について検討を深める。

大型車や連結車はトレッドに対する重心高が高く, 横転(口 一ルオーバ) に対して不利な構造である. 横転は, 車両のダ メージが大きく, 乗員が車外に放出されると最悪の事態を招 きかねない，さらに，車の規模から交通渋滞といった二次災 害を引き起こすことが少なからずある，トルクの吸収効果か らロールモーメントに直接作用するというジャイロ機能は, 横転防止のための有効な手段と考えられる. 横転防止に対す るジャイロ機能の有效性を, 数值シミュレーションを用いて 検証するとともに, 求めた制御量に対し, ジャイロ機能とエ ネルギ貯蔵の両立の可能性についても検討を行った.

\section{2.エエネルギ貯蔵特性}

車載用エネルギ貯蔵装置として, 二次電池, 電気二重層型 キャパシタ, フライホイールが有力視されている. 各エネル ギ貯蔵装置の特徴を図 2.1 に示す.フライホイールは, 出力 密度が高いが比較的損失の大きいという特徽から, 制動エネ ルギ回生やハイブリッドシステムでの短時間貯蔵に適し, 大 型貨物車両や LRV, 鉄道車両との相性がいいと考えられる. フライホイールの特性を把握するため, 本研究室では千葉実 験所にフライホイール評価試験装置を導入した.

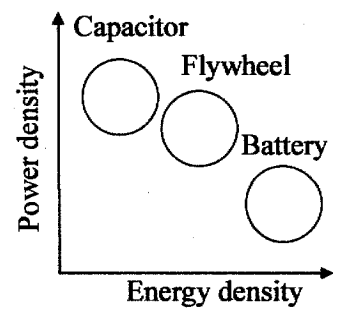

Fig. 2.1 Characteristics of energy storage

\section{3. 車両モデル}

車両重量 $10.5 \mathrm{t}$ の大型車のモデル化を行った. 前車体と後 車体との分割点は，フレームのねじりに関する一次モードが ホイールベース中心にあるものとして，ホイールベースの中 心に設定した. 重心位置は, y,z 方向に関しては各車体の中心 とし, $\mathrm{x}$ 方向の位置は車両全体の重心位置と等しくなるよう に設定した.また, 大型車におけるフレームのねじり剛性は, 前車体と後車体に分割し，回転ばねを用いることにより模擬 し, サスペンション構造については，ロールセンタの位置を 車体に対し固定し，ロールセンタ回りの回転自由度及び車軸 の上下方向の自由度を許す構造として模擬した.ささらに，口

[No.07-51] 日本機械学会第 16 回交通・物流部門大会講演論文集 [2007-12.12 14. 川崎] 
ールセンタ回りに回転ばねを加え，車軸と車体間にばね，ダ ンパを加えた.

3.1 座標系 慣性座標系 $O-X Y Z$ に対し, 車体の回転中 心を原点, 車両進行方向を $x$ 軸, 鉛直上向きを $z$ 軸とし, 慣 性座標系の $Z$ 軸まわりに $\psi$ 回転させる座標系 $o-x y z$ を設定 する. 座標系 $o-x y z$ を図 3.1 (a) に示す. 車体重心を原点とし, 座標系 $o-x y z$ を $x$ 軸まわりに $\phi$ 回転させる車体座標系 $G-\xi_{1} \eta_{1} \zeta_{1}$ を設定する. 車体座標系 $G-\xi_{1} \eta_{1} \zeta_{1}$ を図 $3.1(\mathrm{~b})$ に示す. 車体座標系 $G-\xi_{1} \eta_{1}, \zeta_{1}$ を $\eta_{1}$ 軸まわりに $\theta$ 回転させるジンバル 座標系 $G-\xi_{2} \eta_{2} \zeta_{2}$ を設定する. ジンバル座標系 $G-\xi_{2} \eta_{2} \zeta_{2}$ を $\zeta_{3}$ 軸まわりに $\Omega t$ 回転させるジャイロ座標系 $G-\xi_{3} \eta_{3} \zeta_{3}$ を設定す る. ジンバル座標系 $G-\xi_{2} \eta_{2} \zeta_{2}$ 及びジャイロ座標系 $G-\xi_{3} \eta_{3} \zeta_{3}$ を 図 3.1 (c)に示す．また，ジャイロを車載したときの横転防止 図を図 3.2 に示す.

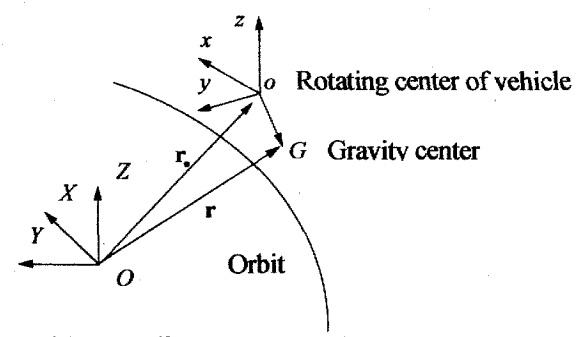

(a) Coordinate system of $o-x y z$
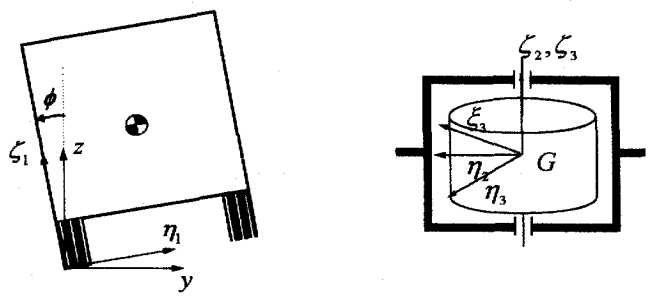

(b) Coordinate system of $G-\xi_{1} \eta_{1} \zeta_{1}$

(c) Coordinate system of $G-\xi_{2} \eta_{2} \zeta_{2}, G-\xi_{3} \eta_{3} \zeta_{3}$

Fig. 3.1 Coordinate systems

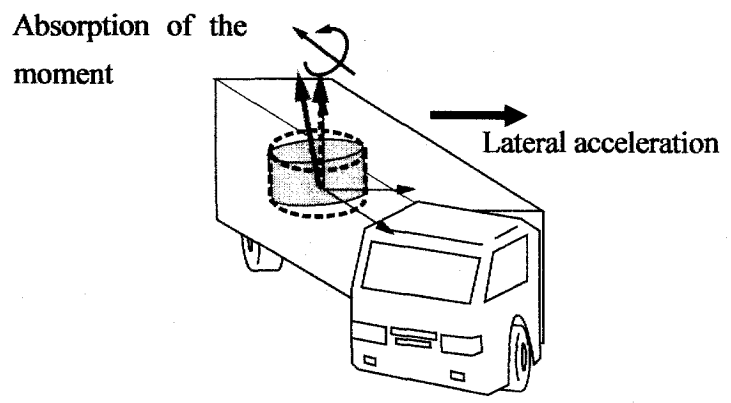

Fig .3.2 Rollover prevention

\section{2 主な記号}

$\mathbf{I}_{\mathbf{1}}=\operatorname{diag}\left(\begin{array}{lll}I_{51} & I_{\eta 1} & I_{51}\end{array}\right):$ 車体の慣性テンソル

$\mathbf{I}_{3}=\operatorname{diag}\left(\begin{array}{lll}I_{\xi_{3}} & I_{\xi_{3}} & I_{5^{3}}\end{array}\right)$ : ジャイロの慣性テンソル

$m_{v}$ : 車体の質量

$m_{G}$ : ジャイロの質量

$l:$ 車体回転中心から車体重心までの距離

$V$ : 車体の走行速度
$\Omega$ : ジャイロの回転角速度

$k$ : ジンバル軸まわりのばね定数

$c$ : ジンバル軸まわりの粘性減衰係数

$\phi$ : 鉛值軸に対する車体傾斜角

$\theta:$ ジンバル角

$g:$ 重力加速度

$b$ : トレッド

$h$ : 重心高さ

$\alpha: \tan ^{-1}(b / 2 h)$

$J$ : ジャイロの $\zeta_{3}$ 軸まわりの慣性モーメント

$L:$ : シャイロの $\zeta_{3}$ 軸まわりの角運動量

$\Omega_{\max }$ : ジャイロの $\zeta_{3}$ 軸まわりの上限角速度

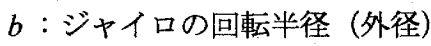

$\alpha$ : ジャイロの外径と内径の比 $(=a / b)$

$\beta$ : ジャイロの下限角速度と上限角速度との比 $\left(=\Omega_{\min } / \Omega_{\max }\right)$

$\rho:$ : ャイロの材料密度

$\sigma_{\max }:$ ジャイロの引張強さ

$K_{a}:$ 安全率

$K_{\Omega}$ : 有効エネルギ率

3.3 運動方程式運動方程式は以下のように導かれる. $\left\{I_{\bar{G}}+I_{53}+\left(m_{v}+m_{G}\right) l^{2}\right\} \ddot{\phi}$

$=\left(m_{V}+m_{G}\right) l V \dot{\psi} \cos (\alpha-\phi)-\left(m_{y}+m_{G}\right) g l \sin (\alpha-\phi)$

$-I_{53} \Omega \dot{\theta} \cos \theta+I_{53} \dot{\psi} \dot{\theta} \cos \phi-I_{53} \Omega \dot{\psi} \cos \theta \sin \phi$

$+\left(I_{m}-I_{51}\right) \dot{\psi}^{2} \sin \phi \cos \phi-\left(m_{v}+m_{G}\right) l^{2} \dot{\psi}^{2} \sin (\alpha-\phi) \cos (\alpha-\phi)$

$I_{\zeta_{3}} \ddot{\theta}+c \dot{\theta}+k \theta$

$=I_{\zeta_{3}} \Omega \dot{\phi} \cos \theta-I_{\zeta_{3}}(\ddot{\psi} \sin \phi+\dot{\psi} \dot{\phi} \cos \phi)-I_{63} \Omega \dot{\psi} \cos \phi \sin \theta$

車両のロール角фについて十分小さいとし, 微小項を無視 すると，次式で表される.

$\left[\begin{array}{cc}I & 0 \\ 0 & I_{53}\end{array}\right]\left[\begin{array}{l}\ddot{\phi} \\ \ddot{\theta}\end{array}\right]+\left[\begin{array}{cc}0 & I_{53} \Omega \\ -I_{53} \Omega & c\end{array}\right]\left[\begin{array}{l}\dot{\phi} \\ \dot{\theta}\end{array}\right]$

$+\left[\begin{array}{cc}-m l(V \dot{\psi} \sin \alpha+g l \cos \alpha) & 0 \\ 0 & k+I_{53} \Omega \dot{\psi}\end{array}\right]\left[\begin{array}{l}\phi \\ \theta\end{array}\right]$

$=\left[\begin{array}{c}m l(V \dot{\psi} \cos \alpha-g l \sin \alpha) \\ 0\end{array}\right]$

3.4 ジンバル角の制御（3.3)式は, ジンバル角 $\theta$ 回りの 運動方程式において, 車両のヨーレートによりジャイロの運 動が異なることを示しており，鉄道車両にくらべヨーレート の比較的大きい自動車では顕著に差が表れると予想できる. また, ジンバル角が大きくなるにつれ，車両のヨー運動への 影響も大きくなると予想される.

そこで, ジャイロによる外乱トルクの吸収効果, 車載時に おける許容運動を考慮し, ジンバル角変位を $30 \mathrm{deg} に$ に抑制す ることとする．横転防止制御の流れを図 3.3 に示す．横転の 危険性のある横加速度が発生したとき，はじめに，外部ジン バルを拘束し，内部ジンバルにより外乱トルクを吸収する. そして内部ジンバル角が 30degに達したとき， ヨー運動への 影響を小さくするため，内部ジンバルを固定する. 


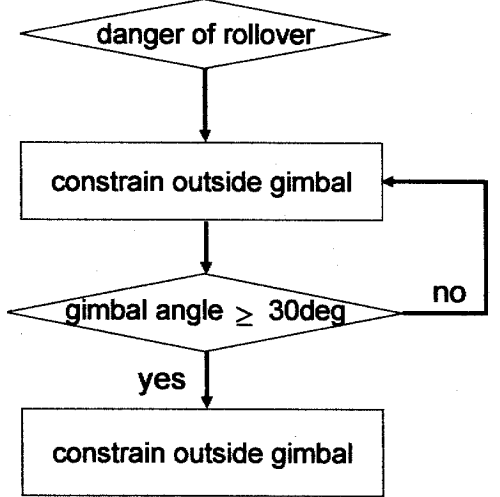

Fig. 3.3 Flow of control

4. 横転防止効果の数値シミュレーション

3 章で示した車両モデルを用い，大型貨物車両および連結 車両の横転防止に関する有効性について，数值シミュレーシ ヨンを用いて検証した．尚，車両モデルは MBD 汎用ソフト である SIMPACK を用いて作成した。

4.1 計算条件 車速 $80 \mathrm{~km} / \mathrm{h}$ において実舵角 $6 \mathrm{deg}$ を時刻 4sにおいてステップ上に与えるものとする. 本条件は発生す る横加速度がロールオーバ条件に近く，制御なしでは横転の 危険性がある条件である．本計算モデルにおける横加速度の ロールオーバ条件は, 約 $0.58 \mathrm{~g}$ である. ジャイロの慣性テン ソルは，千葉実験所における評価試験装置を参考にし， I $=\operatorname{diag}(7.57 .57 .5)$ （単位は $\mathrm{kgm}^{2}$ ) とし，回転角速度を $0 \mathrm{rad} / \mathrm{s}, \quad 500 \mathrm{rad} / \mathrm{s}, \quad 750 \mathrm{rad} / \mathrm{s}, \quad 1000 \mathrm{rad} / \mathrm{s},-500 \mathrm{rad} / \mathrm{s}, \quad 750 \mathrm{rad} / \mathrm{s}$ $-1000 \mathrm{rad} / \mathrm{s}$ と変化させて計算した.

また, ジャイロの制御開始はロール角が 5degになった時と 設定した. ジンバル角は30deg または，-30degにおいて拘束 されるようにした．本数值シミュレーションにおいては，ば ねにより拘束を行うように設定している，ただし，750 $\mathrm{rad} / \mathrm{s}$, $1000 \mathrm{rad} / \mathrm{s}$ の条件においてはジンバル角は20degにおいて拘束 されるものとした.

4.2 計算結果計算結果より, $10.5 \mathrm{t}$ 車両では, 回転軸 の向きに関わらず，慣性モーメント $7.5 \mathrm{kgm}^{2}$ のフライホイー ルで 750 $\mathrm{rad} / \mathrm{s}($ 約 7000 $\mathrm{rpm}$ )以上，即ち角運動量で約 $5600 \mathrm{Nms}$ 以上の条件で横転を防止できることが分かった．また，解析 では，接地した際の路面からの跳ね返りにより，ロール角が 振動的になった. ジンバル角を 30 度までに拘束することによ って, 車両のヨー軸回りの回転運動との影響は少なく，フラ イホイール回転軸の向きによるジャイロの効果の差はほとん どでないことが確認できた.

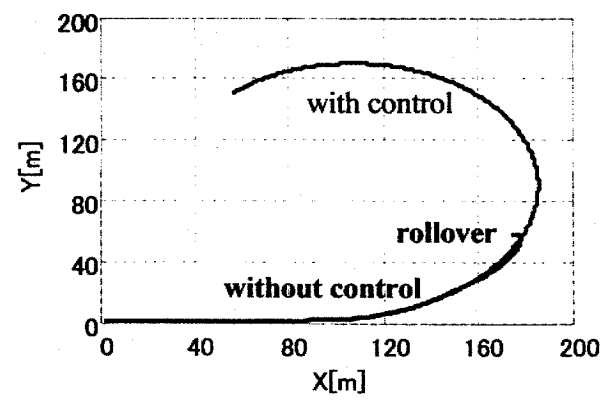

Fig. 4.1 Vehicular swept path

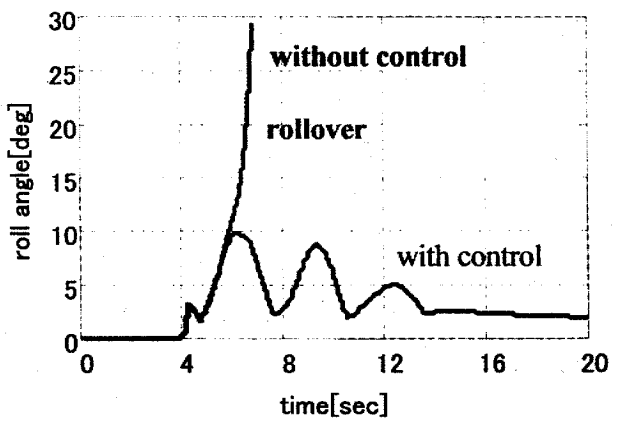

Fig. 4.2 Roll angle

\section{5. エネルギ貯蔵とジャイロ機能の両立}

本章では，エネルギ貯蔵とジャイロ機能の両立性に関する 検討を行う。車両が一般道路を走行するとき，フライホイー ルは，車両の駆動時に車両一駆動トルクを供給し，逆に，制 動時には車両の運動エネルギを吸収する.この過程において, ジャイロの角運動量は変化するが，その值が常に横転防止制 御に必要な值より大きければ, フライホイールは常にジャイ 口機能としても働くことができる．そこで，大型車両が代表 的な 10 モード走行を行ったときのフライホイールの両立性 について，数值シミュレーションによる解析を行う.

5.1 モード走行 モード走行には目的によって様々なも のがあるが，ここでは，市街地に近い10 モードを想定し，そ の間におけるジャイロの回転数や角運動量，エネルギ変化に ついて計算する. 10 モードを図 5.1 に示す.

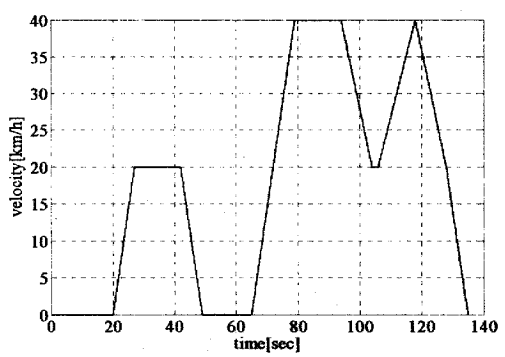

Fig. 5.1 10mode

5.2 フライホイールの成立条件フライホイールの成 立条件は，次式のように表される。

$\frac{\beta^{2}}{2} J \Omega_{\max }^{2} \leq \frac{L^{2}}{2 J} \leq \frac{1}{2} J \Omega_{\max }^{2}$

また，ジャイロの許容回転角速度は，安全率を考慮すると， 以下の式で表される.

$\Omega_{\max } \approx \frac{1}{b} \sqrt{\frac{\sigma}{K_{a} \rho}}$

これらを考虑すると，以下のような条件をみたすとき，ジ ヤイロ機能が成立することになる。

$\sqrt[4]{\frac{2 L}{\pi\left(1-\alpha^{4}\right)^{2}} \sqrt{\frac{K_{a}}{\sigma \rho}}} \leq b \leq \sqrt[4]{\frac{2 L}{\pi \beta\left(1-\alpha^{4}\right)^{2}} \sqrt{\frac{K_{a}}{\sigma \rho}}}$

横転防止制御システムで必要とされるジャイロの角運動量 は, 4.2 節で約 $5600 \mathrm{Nms}$ であることが分かった. 下限回転数 で回転しているときの角運動量がこの值になるためのジャイ 口の質量, 半径を求めた結果を表 5.1 に示す. ただし $\alpha, \beta$ の 
值はともに 0.5 とし, 安全率は 2 とする。 また, ジャイロに 用いる材料として, 高張力鋼, マレージング鋼, CFRP の 3 種類について比較する.これらの材料の物性值を表 5.2 に示 す.

Table5.1 Numerical values

\begin{tabular}{|c|c|c|c|}
\hline & high-tensile steel & maraging steel & CFRP \\
\hline radius [mm] & 284 & 222 & 257 \\
\hline mass[kg] & 282 & 205 & 64 \\
\hline
\end{tabular}

Table5.2 Properties

\begin{tabular}{|c|c|c|c|}
\hline & high-tensile steel & maraging steel & CFRP \\
\hline tensile strength[MPa] & 1024 & 2450 & 3820 \\
\hline density $\left[10^{3} \mathrm{~kg} / \mathrm{m}^{3}\right]$ & 7.8 & 7.9 & 1.6 \\
\hline
\end{tabular}

5.3 シミュレーション結果 5.2 節で求めたジャイロの 諸元を用い, 各材料に対して求めた, 10 モードにおける回転 角速度, 角運動量, エネルギ変化を図 5.2〜 5.4 に示す. また, 簡単のため, フライホイールのエネルギの授受はすべて, 大 型車の運動エネルギとの間に行われるものとした. 図より, 車両の速度が最も大きい時刻において，フライホイールの角 運動量の值は最小值の $5600 \mathrm{Nms}$ をとり, その他の時刻につい ても, 横転防止システムに必要な角運動量を上回っているこ とがわかる．また，どの時刻においても，CFRPを用いたフ ライホイールのエネルギ量が他の材料に比べて $1 \mathrm{kWh}$ 程度大 きいことがわかる. さらに表 5.1 より，軽量という点におい ても, CFRPは他の材料より優れているということができる.

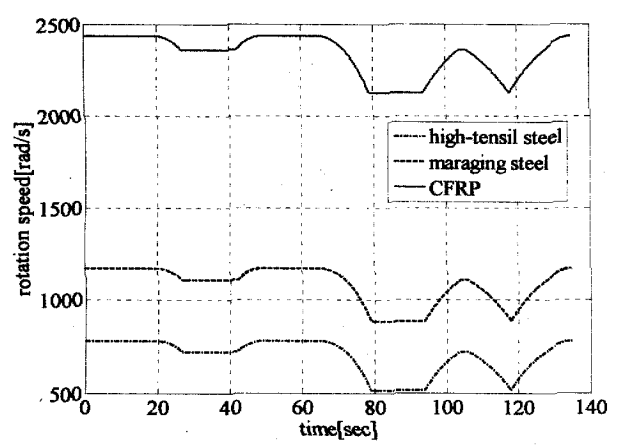

Fig 5.2 Fluctuation of rotation speed

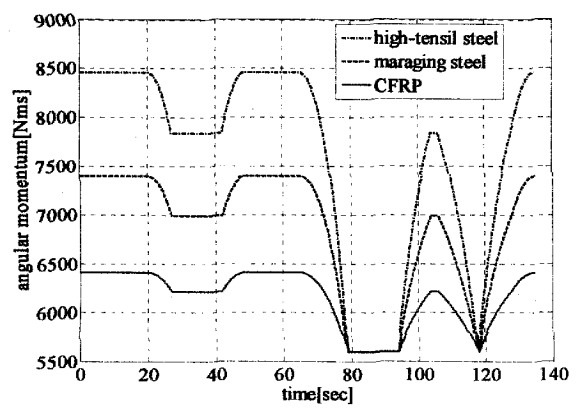

Fig 5.3 Fluctuation of angular moment

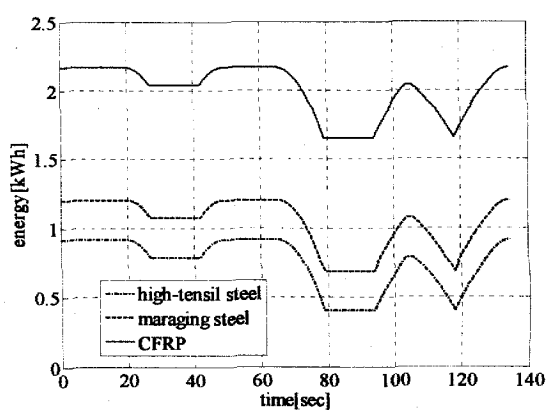

Fig 5.4 Fluctuation of flywheel energy

\section{6. 結言}

本研究では, フライホイールエネルギ貯蔵装置のジャイロ 機能を有効に活用した車両運動制御の提案を行い，大型自動 車の横転防止制御の可能性を検討した。基磷的な理論解析を 踏まえ, 数值シミュレーションを用いて、10.5t の車雨モデル において，ジンバル角を士30deg に制限したジャイロを車載 することによって, 大型車両の横転防止への有効性を示した。 さらに，エネルギ貯蔵とジャイロ機能の両立について検討を 行い, ジャイ口機能を有効活用するための角運動量を持ちな がら，エネルギ貯蔵装置としての要件を満たせることを示し た。また、フライホイールの材料として, CFRP が優れてい ることを確認した。

\section{7. 参考文献}

(1) Henning,U., Thoolen,F., Lamperth,M., Berndt,J., Lohner,A., Janig,N., Light Rail Transit with Ultralow Emission Hybrid Tractoin Drive System, Proceedings of International Symposium on Speed-up and Service Technology for Railway and Maglev Systems, 2006,282

(2) Den Hartog, J. P., Mechanical Vibrations, 106, (1956), McGraw-Hill

(3) Kanki,H., Nekomoto,Y., Monobe,H., Ogura,H., Kobayashi,K., Development of CMG Active Vibration Control Device for Gondla. JAME International Journal Series C Vol37 No.3,Sept. 1994,468

(4) Okamoto,H., Lin,S., Kotani,M., Yabuno,H., Suda,Y., Stabilizatoin Control for Hunting Motion of Railway Vehicle by Gyroscopic Damper, Proceedings of $10^{\text {th }}$ Mini Conference on Vehicle System Dynamics, Identification and Anomalies(VSDIA2006), Budapest

(5) 黒河: コントロールキーメントジャイロを用いた人工衛星の姿 勢制御，システム/制御情報,33-4 (1989),157

(6) 須田義大, 王文軍, 小谷学: 新方式による車両の姿勢制御に関 する研究，第 15 回交通・物流部門大会講演論文集, No.06-52, pp253-256, 2006

(7) 須田義大, 王文軍, 小谷学: ジャイロを用いた車体傾斜システ ムに関する研究，日本機械学会年次大会講演論文集，No.06-1 pp369-370, 2007

(8) 須田義大, 小谷学, 王文軍: 横転防止制御システムに関する研 究, 日本機械学会年次大会講演論文集, No.07-1, pp365-366, 2007 